Special Issue of the 6th International Congress \& Exhibition (APMAS2016), Maslak, Istanbul, Turkey, June 1-3, 2016

\title{
Investigation of Mechanical Properties of MIG-Brazed 304 Stainless Steel and EN 10292 Galvanized Steel Joints using Different Current Intensity
}

\author{
F. VAROL* \\ Vocational School of Karasu, Sakarya University, Karasu, Sakarya, Turkey
}

\begin{abstract}
In this study, 304 stainless steel and EN 10292 galvanized steel plates having $1 \mathrm{~mm}$ thickness were joined by copper-based S Cu $6100(\mathrm{CuAl})$ wire in gas metal arc brazing technique. Argon was used as shielding gas and brazing operations were done with gas flow speed as $12 \mathrm{~L} / \mathrm{min}$. Brazing operations were done with seven different weld currents as 40, 45, 50,55,60,65, and 70 A. Having accomplished the brazing operations, tensile strengths of joints were tested, and micro and macro-structures of joints were investigated in order to see the joinability of 304 stainless steel and EN 10292 steels using different current intensity by gas metal arc brazing technique.
\end{abstract}

DOI: 10.12693/APhysPolA.131.34

PACS/topics: 81.70.-q, 81.70.Bx

\section{Introduction}

Recently, it becomes important in automotive industry to improve gas mileage by reducing total weight of vehicles while maintaining their level of safety. Therefore, using high strength materials, which provide higher strength for automobile body parts, has rapidly increased in the sheet metal industry [1-3]. Most of 304 stainless steels harden with cold forming. Thanks to increasing strength, material thickness decreases and that provides decline in material weight and price. Almost all stainless steels can easily be shaped by methods of cutting, brazing, hot and cold shaping [4]. The car assembly industries have recently been using zinc-coated carbon steel sheets in passenger car bodies because they combine good mechanical properties, good corrosion resistance and low purchase cost of this material [5, 6]. The EN 10292 galvanized steel sheets are widely used in construction with corrosion resistance and especially in the automotive industry [7]. In car assembly, where conventional welding processes like gas metal arc welding (GMAW) are used, the zinc coating is subject to severe evaporation and oxidation, leaving the weld bead and part of the base metal unprotected against subsequent oxidation. To reduce the risk of zinc evaporation, new welding processes with a low heat supply have begun to gain ground, for example metal inert gas (MIG)-brazing, which combines the advantages of the MIG process (high deposition rate, high welding speed and adaptable to automation) and brazing (without any intense fusion of the welded parts and without any appreciable alteration of the mechanical properties of the base metal and the coating applied) $[8,9]$.

\section{Materials and equipments}

304 stainless steel and EN 10292 galvanized steel plates was used in this study. In the tests the galvanized

\footnotetext{
*e-mail: fvarol@sakarya.edu.tr
}

steel plates were $1 \mathrm{~mm}$ thickness, with $7.5 \mu \mathrm{m}$ zinc coating. Steel plates were cut $200 \times 200 \times 1 \mathrm{~mm}^{3}$. The sheets were positioned end to end to allow gaps between them $0.5 \mathrm{~mm}$, and were subjected to joining by MIG-brazing process. The filler metal was a solid wire with a diameter of $1 \mathrm{~mm}$, classified as AWS ERCuAl8, which is a copper-based, torch angle of $90^{\circ} \mathrm{C}$. Argon was used as the shielding gas at a flow rate of $12 \mathrm{~L} / \mathrm{min}$. The surface of the samples was cleaned by acetone before MIGbrazing. MIG-brazing operations were carried out in a current control MIG-brazing machine having $300 \mathrm{~A}$ capacity. The current values for brazing operation were determined as $40,45,50,55,60,65$, and $70 \mathrm{~A}$ in butt joint. Seven sets of welding parameters of different heat inputs were selected, as shown in Table I. The heat input, $H I$, is calculated using the equation

$$
\begin{aligned}
& H I_{\text {linear }}=\frac{(60 U I) \eta}{V}, \\
& H I_{\text {normalized }}=\frac{H I_{\text {linear }}}{e},
\end{aligned}
$$

where $\eta_{\text {MIG }}=0.7$ is the arc efficiency factor, $e$ thickness $[\mathrm{mm}], U$ and $I$ are the mean values for the arc voltage, respectively, for the current intensity and $V[\mathrm{~cm} / \mathrm{dak}]$ is the brazing speed [10].

TABLE I

Chemical composition [\%] of AISI 304 austenitic stainless steel (A) and EN10292 galvanized steel (B).

\begin{tabular}{c|c|c|c|c|c|c|c|c}
\hline \hline & $\mathrm{C}$ & $\mathrm{Si}$ & $\mathrm{Mn}$ & $\mathrm{P}$ & $\mathrm{S}$ & $\mathrm{Cr}$ & $\mathrm{Ni}$ & $\mathrm{N}$ \\
\hline $\mathrm{A}$ & 0.08 & 0.75 & 2 & 0.045 & 0.003 & $18-20$ & $8-10$ & 0.051 \\
$\mathrm{~B}$ & 0.11 & 0.5 & 1 & 0.03 & 0.025 & 13.11 & - & -
\end{tabular}

\section{Results and discussion}

To measure the standard joint strength, the tensile testing was conducted at first. The experiments showed that most of tensile test specimens fractured from the base metal EN 10292 galvanized steel. 40, 45, 50, 55, 60, 65, and $70 \mathrm{~A}$ currents showed that the strength of the joint zone was higher than that of the galvanized steel zone and the $\mathrm{CuAl} 8$ filler zone. It was obvious that the joint 


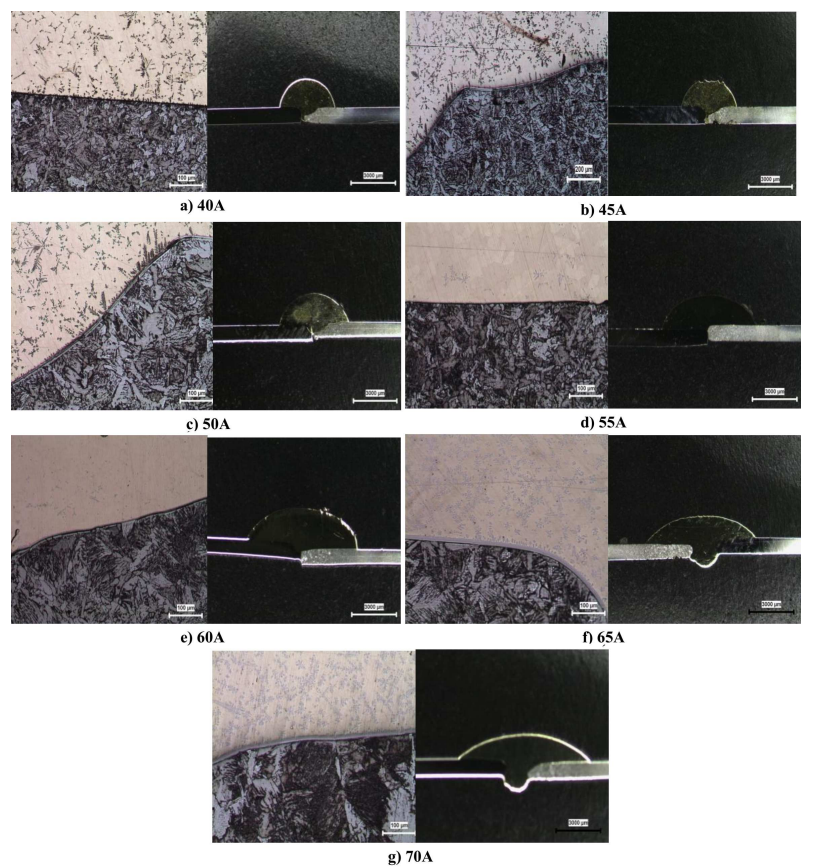

Fig. 1. Macro and micro appearance of the brazing seams for different current intensity: (a) macro and micro appearance of $40 \mathrm{~A}$, (b) $45 \mathrm{~A}$, (c) $50 \mathrm{~A}$, (d) $55 \mathrm{~A}$, (e) $60 \mathrm{~A}$, (f) $65 \mathrm{~A}$, (g) $70 \mathrm{~A}$ in EN10292 and stainless steels.

zone was strengthened. In Fig. 1a-e 40, 45, 50, 55, 60 A, insufficient wetting occurred as a result of low heat input. Having examined the strength values in Table II, it was observed that strength increased with the increase of current intensity, which were parallel with heat input and wetting. When analyzed bending test results, no fracture was observed in the joint zone.

TABLE II

Experimental results for different MIG-brazing gap.

\begin{tabular}{c|c|c|c}
\hline $\begin{array}{c}\text { Current } \\
\text { intensity [A] }\end{array}$ & $\begin{array}{c}\text { Tensile } \\
\text { strength [MPa] }\end{array}$ & $\begin{array}{c}\text { Bending } \\
\text { force [N] }\end{array}$ & $\begin{array}{c}\text { Heat } \\
\text { input [J/cm] }\end{array}$ \\
\hline 40 & 380 & 400 & 810 \\
45 & 420 & 404 & 920 \\
50 & 435 & 406 & 1030 \\
55 & 455 & 415 & 1150 \\
60 & 472 & 420 & 1275 \\
65 & 483 & 425 & 1400 \\
70 & 476 & 440 & 1520
\end{tabular}

Figure 2 shows the measured microhardness value of the joints for different brazing current intensity. It was seen that microhardness value was highest at HAZ and the HAZ hardness was higher than that of the copper filler and base material. Macro and microstructures appearance of the brazing seams for different current intensity are shown in Fig. 1. The molten metal wetted the steel better when using 65, $70 \mathrm{~A}$ current intensities, comparing the samples brazed in $65,70 \mathrm{~A}$ at lower heat input to samples brazed in 40, 45, 50, 55, 60 A. During the arc brazing process, it was observed that the number
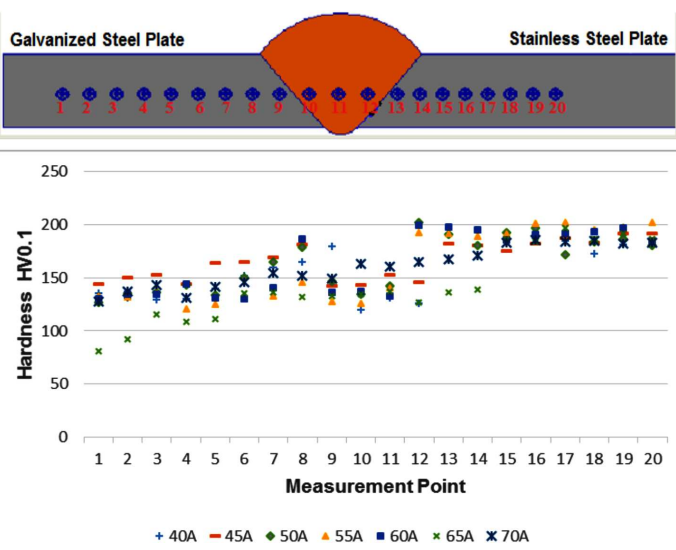

Fig. 2. Hardness profile in heat affected zone in EN10292 and stainless steels.

of dendrites increased on the surface of the joint zone. These dendrites' action caused micro iron particles to melt and migrate, and to become distributed throughout the filler metal zone.

\section{Conclusion}

- 10292 galvanized steel and 304 stainless steel were brazed. It was observed that strength increased with the increase of current intensity. The experiments showed that most of tensile test specimens fractured from the base metal EN 10292 galvanized steel. When analyzed bending test results, no fracture was observed in the joint zone.

- MIG-brazing method provided lower heat input in comparison with other fusion methods.

- The molten metal wetted the steel better when using 65, 70 A current intensities, comparing the samples brazed in $65,70 \mathrm{~A}$ at lower heat input to samples brazed in 40, 45, 50, 55, $60 \mathrm{~A}$.

\section{References}

[1] F. Ozturk, S. Toros, S. Kilic, Iron Steel Res. Int. 16 , 41 (2009).

[2] U. Ozsarac, J. Mater. Eng. Perform. 21, 748 (2012).

[3] S. Aslanlar, Mater. Des. 27, 125 (2006).

[4] R. Yılmaz, M. Tumer, Int. J. Adv. Manuf. Tech. 67, 1433 (2013).

[5] D. Iordachescu, L. Qintino, R. Mirenda, G. Pimenta, Mater. Des. 27, 381 (2006).

[6] R.F. L1, Z.S. Yu, K. Q1, Trans. Nonferr. Met. Soc. China 16, 397 (2006).

[7] AWS Welding Processes, Welding Handbook, Vol. 2, 8th ed., AWS, Miami 1991.

[8] A.F. Rangel, L.A. Matlakhova, R.P. Da Rocha Paranhos, A.N. Matlakhov, Wel. Inter. 20, 889 (2006).

[9] Z.S. Yu, Y.Y. Q1an, R.F. Li, F.M. Zhou, Mater. Sci. Tech. Ser. 10, 1399 (2003).

[10] F. Varol, E. Ferik, U. Ozsarac, S. Aslanlar, Mater Des. 52, 1099 (2013). 